\title{
The Database of the Catalogue of Clinical Practice Guidelines Published via Internet in the Czech Language - The Current State
}

M. Zvolský
${ }^{1}$ Centre of Biomedical Informatics, Institute of Computer Science AS CR, v.v.i.

Supervisor: Doc. Ing. Arnošt Veselý, Csc.

\section{Summary}

Since the nineties the publication activity of expert authorities in the field of Clinical practice guidelines (CPGs) has increased. During the first decade of the 21 st century the Internet has become one of the most important publishing media for CPGs due to the popularity of sharing information in an electronic form. Nowadays, approximately 107 Czech expert societies publish about $731 \mathrm{CPG}$ on the Internet according to previous explorations of web sites of Czech expert medical societies and practical experience with previous operation of the Catalogue of Clinical Practice Guidelines. CPG documents can be used by physicians and other clinical employees in clinical praxis and education, by administrative authorities, by health policy makers or by patients. Information in these documents is also essential in the development of clinical information systems and decision support systems.

The database of the Catalogue of Clinical Practice Guidelines takes a survey in the appearance of CPGs on free accessible web sites of expert societies or periodicals guaranteed by expert societies. The database stores bibliographical data, information about the recency and the quality of CPGs and information about the existence of web tools or formal models based on these CPGs.

The database contains 562 records of CPGs published by Czech expert medical societies. 212 records are accessible via the web interface of the Catalogue of Clinical Practice Guidelines.

Keywords: Internet, World Wide Web, database, clinical practice guideline, clinical practice, evidence-based medicine, formalisation, GLIF (Guideline Interchange Format), doctor of medicine, decision support systems

\section{Introduction} 1.1 Definition of Clinical practice
guidelines in the Czech language Clinical practice guidelines (CPGs) are an important part of the decision process on all levels of health care providing [1]. A recognized definition of these documents is they are "Systematically developed statements that can be used to accomplish appropriate specific health care decisions, services and outcomes" [2].

In spite of the big number of CPGs in Czech expert publications, they have often different designations such as "medical recommendation", "recommended procedure", "methodical instruction", "guideline", "standard" and others. The Czech Society of Cardiology uses both "guideline" (the word "guideline" is adopted into the Czech language) and "recommended practice" ("doporučený postup" in original) as synonyms. The Czech Medical Association of J. E. Purkyně uses terms "therapeutic standard" („léčebný standard") and recommended practice („doporučený postup"). The terms used started to be defined accurately in the Czech expert literature in recent years [1], [3], [4], [5].

\subsection{Publication activity of expert medical societies}

Documents defining health care in particular clinical relations are created on several levels. Documents with supreme legitimacy are published by the World Health Organization. Other documents published by international and national expert institutions have often geographically limited acceptance. Documents published by individual health care institutions have only a local sphere of action.

In the following text we use only CPGs with relevance on the territory of the Czech
Republic. They can be created by Czech national expert societies or translated or adopted from international CPG with wider acceptance.

Standards of health care are not prescribed by imperative legal rules in the Czech law [6]. Adequacy of the health care is evaluated (e.g. by a competent supervisory authority in case of a mistake) as "lege artis" or "non lege artis". Only an attending physician can make clinical decisions and selects the best clinical care. They decide not only on the basis of existing CPGs but they also judge the actual condition of the particular patient in its complexity.

Professional medical societies associated in the Czech Medical Association of Jan Evangelista Purkyně are reputable authorities for publishing CPGs in the Czech Republic. The present number of these societies is 107 [5]. Only some of them systematically develop documents of the normative nature defining administration of the health care in the given clinical conditions (see Table 1) [7]. The Czech Medical Chamber, Czech Dental Chamber, Ministry of Health, National Institute of Public Health or Chief Public Health Officer are other potential publishing authorities of CGPs in the Czech Republic.

There are several ways for CPG document publishing and dissemination. In a printed version CPGs can be an article in an expert periodical of the professional medical society (e.g. Cor et Vasa, Czech Society of Cardiology) or an individual brochure (e.g. series Recommended Diagnostic and Therapeutic Practice for General Practitioners, Society of General Practice). 
Tab. 1. Numbers of CPGs electronically published via web sites of Czech professional medical societies or their official periodicals, year 2009 (showing only societies with eight or more documents).

\begin{tabular}{|c|c|}
\hline Name of expert society & Number of CPGs \\
\hline Society of General Practice & 47 \\
\hline Czech Society of Cardiology & 24 \\
\hline Czech Society of Dermatology and Venereology & 36 \\
\hline Czech Society of Gastroenterology & 14 \\
\hline Czech Society of Neurology & 18 \\
\hline Czech Pneumological and Phthisiological Society & 22 \\
\hline Czech Society of Angiology & 8 \\
\hline Czech Diabetes Society & 13 \\
\hline Czech Society of Hepatology & 18 \\
\hline Czech Society for Oncology & 79 \\
\hline Czech Rheumatological Society & 9 \\
\hline Czech Society of Clinical Biochemistry & 34 \\
\hline Czech Society for Atherosclerosis & 10 \\
\hline Czech Medical Society for Infectious Diseases & 19 \\
\hline Czech Society for Emergency and Disaster Medicine & 17 \\
\hline Czech Society of Pathology & 9 \\
\hline Czech Society for Transfusion Medicine & 8 \\
\hline Czech Radiological Society & 13 \\
\hline Czech Society of Hematology & 14 \\
\hline Czech Society of Anaesthesiology and Intensive Care Medicine & 13 \\
\hline Czech Medical Association of J.E. Purkyně & 305 \\
\hline
\end{tabular}

In an electronic version CPGs are articles in electronic versions of expert periodicals of professional medical societies (e.g. Vnitřni lékařství, The Czech Society of Internal Medicine) [8] or more often as electronic documents located on web sites of professional medical societies (e.g. Czech Society of Dermatology and Venereology) [9]. In all cases the electronic document in an electronic version of textual CPGs is most frequently presented in the Portable Document Format (PDF), the Hypertext Markup Language (HTML) format or the Microsoft Office Document (DOC) format. [7]

As professional societies develop CPGs independently of each other there is no consensus about features of Czech CPGs and individual documents differ not only in formal aspects but also in the amount of information contained. CPGs of the Society of General Practice are an exception, because this society and an established Centre for Clinical Guidelines developed a basic methodology for clinical guidelines. They issue these CPGs in a compact edition of brochures accessible both in printed and electronic versions.

There is an effort for an introduction of standards of clinical care as a part of health care system of the Czech Republic. The National Reference Centre was founded for this purpose. A detailed methodology was assembled for the systematic development of these standards. Individual standards are not open to the public at the present time [9].

\subsection{Catalogue of Clinical Practice Guidelines - the history and goal of the project}

The rich amount of published CPGs, their different forms, the amount of publishing institutions and the number of their web sites where these documents are stored in electronic versions cause problems in searching for the particular document for a specific clinical situation.

The problem of the quality of the looked-up documents arises when using full-text web search engines or general catalogues. Many different organisations and individuals such as health care providers, professional commercial portals, patients, special-interest associations or pharmaceutical companies can publish texts mentioning clinical situations, diagnostics and treatment. These documents may differ from the CPGs in effect or even contradict them.

Specialized portals dedicated to the issue of CPGs exist abroad. They often contain catalogues of electronically published CPGs. The best known CPGs cataloges are the National Guidelines Clearinghouse in the USA [10] and the National Library of Guidelines in the United Kingdom [11] both focused on CPGs in the English language. Catalogues focused on national CPGs arised also in other countries (e.g. http://www.leitlinien.de/, http://www. nzgg.org.nz/). The Guidelines International Network (G-I-N) connects national organisations into the international web. It also has a library with links to the on-line accessible CPGs [12]. Although Czech Národní referenční centrum is a member of G-I-N, there is no link to the Czech CPGs in the International Guideline Library or other foreign or international catalogues. Foreign web services in the field of CPGs have the disadvantage of foreign language web interface, which could be a barrier for some Czech users. 


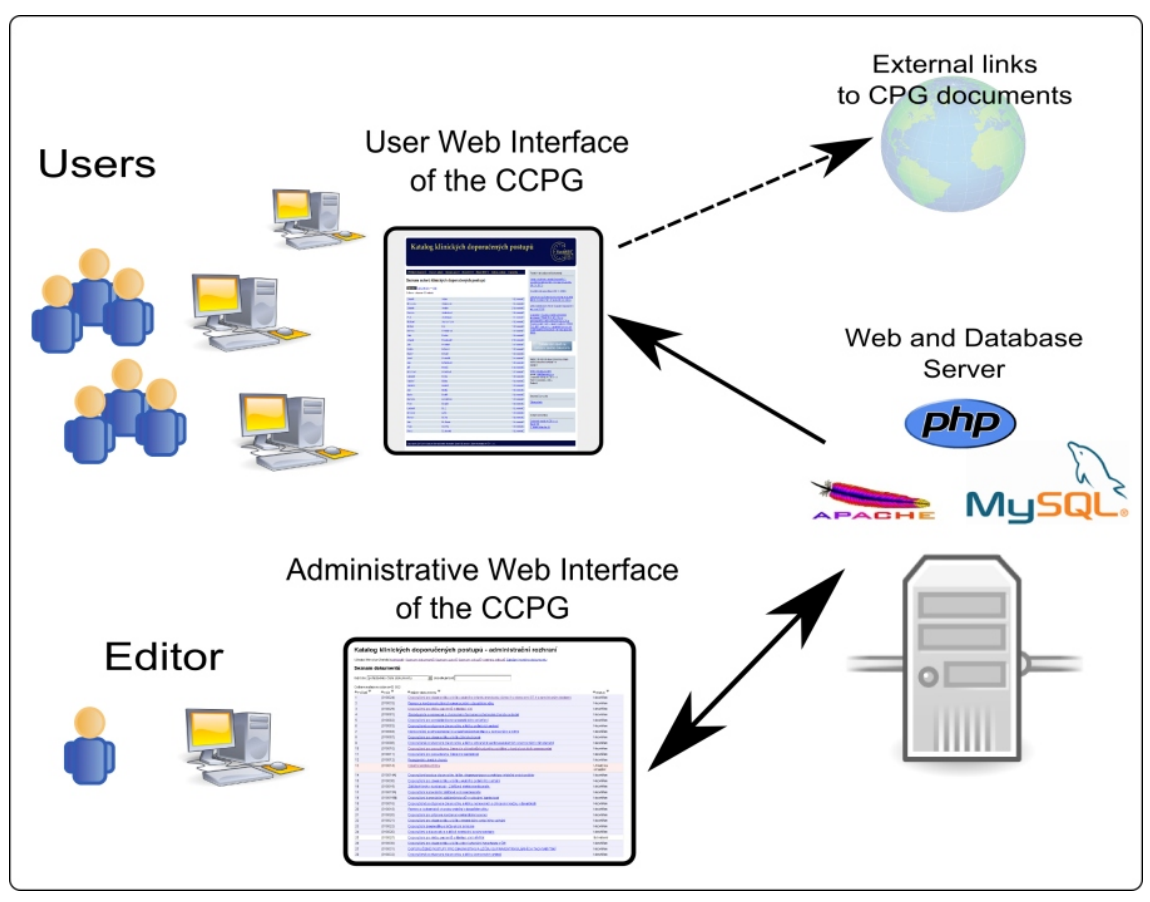

Fig. 1. Catalogue of Clinical Practice Guidelines. a directory of these experts and institutions. In the future we assume to connect a number of links between each CPG document and external bibliographical links (e.g. into Medline or other bibliographical databases). This can create a useful source for educational purposes. Our database is ready for linking information about formal models of CPGs. These models are not included in today's Czech CPGs and they are not available from external sources yet except our previous efforts. Links between CPGs, classification and terminological systems together with future development of formal models of CPGs can compose a valuable informational source for decision support systems [14]. We also consider future extensions of the database with the extension of the Web 2.0 functions of the CCPG portal.
The development of the Catalogue of Clinical Practice Guidelines (CCPG) (former Lékařské doporučené postupy $v \check{C} R$ - Clinical Practice Guidelines in the Czech Republic) started in 2007 [13]. The absence of the general list of electronicaly published Czech CPGs was an impulse to start the development of our catalogue. We focused on CPGs in the Czech language or documents valid for the Czech Republic respectively, which are published via the Internet. We designed a web interface in the PHP scripting language, which alows to display records stored in the MySQL database and their listing according to various criteria. This freely accessible user web interface is placed on the following address http://neo.euromise.cz/kkdp.

Another web interface (administrative interface) is accesible after authentication and it allows adding and editation of records, communication with authors of CPGs and among editors, checking the validity of external links and other functions. The schematic structure of the CCPG project is desribed in Figure 1.

The database of gathered data about several CPG documents has a wider use. Because of a high amount of information about authors and professional societies, the database can serve as a source for
Tab. 2. Structure of the database table documents.

\begin{tabular}{|c|c|c|}
\hline Column name & Data type & Description \\
\hline category_id & $\operatorname{int}(11)$ & category of the CPG document \\
\hline document_abstract & Text & abstract of the CPG document \\
\hline document_actualization & Date & date of the last actualization of the CPG document \\
\hline document_authornote & Text & authors annotation of the CPG document \\
\hline document_contact & Text & authors contact information \\
\hline document_creation & Date & date of creation/authorization of the CPG document \\
\hline document_id & $\operatorname{int}(11)$ & serial number of the CPG document \\
\hline document_iid & varchar(20) & unique coding identification of the CPG document \\
\hline document_inda & Datetime & date and time of the CPG record insertion \\
\hline document_keywords & Text & key words for the CPG document \\
\hline document_Icda & Datetime & date and time of the CPG record change \\
\hline document_Icui & smallint(6) & identification of the user, who made the last change to the CPG record \\
\hline document_note & Text & textual note to the CPG document \\
\hline document_printed & Text & complete title of the printed version of the CPG document \\
\hline document_state & $\operatorname{int}(11)$ & $\begin{array}{l}\text { state of verification of the CPG document record - states whether the record is fully } \\
\text { verified by the editor and should be displayed in the user interface }\end{array}$ \\
\hline document_target_population & Text & target population for the CPG document \\
\hline document_termination & Date & date of the CPG document withdrawal \\
\hline document_title & Text & title of the CPG document \\
\hline document_usid & smallint(6) & identification of the user, who created the CPG record \\
\hline document_views & $\operatorname{int}(11)$ & number of views of the CPG document in the web interface of the CCPG \\
\hline evidence_id & $\operatorname{int}(11)$ & $\begin{array}{l}\text { lowest level of evidence used in the CPG document using the scale of the Oxford Centre } \\
\text { for Evidence-Based Medicine }\end{array}$ \\
\hline document_evidence & Text & definition and description of the levels of evidence used in the CPG document \\
\hline recency_id & smallint(5) & $\begin{array}{l}\text { recency type of the CPG document - concept of document, valid document or obsolete } \\
\text { document }\end{array}$ \\
\hline
\end{tabular}




\section{Methods}

In the concept of the CCPG database we resulted partly from the statement of the Conference on Guideline Standardization (COGS) [15], partly from an inspiration with the National Guideline Clearinghouse [10] with comprehensive details about every CPG document in the "Guideline Summary". These sources were confronted with the real situation of Czech CPG documents, which often do not contain basic identification specification such as the name of the author or the date of an issue. It was not possible to use developed tools for communication with CPG authors for completing CPG records. In the project of CCPG we presume using these tools for intensive communication and cooperation with CPG authors, but we do not dispose of resources comparable with the Agency for Healthcare Research and Quality in the United States, which operates the National Guideline Clearinghouse. It was our aim in the introductory phase to enter information, which is already contained in CPG documents or which can be easily found (e.g. related diagnoses in the ICD-10 classification). So we accented a structured identification specification about authors, time and expert destination of the CPG. We can define another information for example in the universal textual column document_note in the _documents table.

We have been developing the actual version 2.0 of the CCPG since the beginning of the year 2010. We have been using a MySQL version 5.0.41 database as a database environment. The database consists of 49 tables. 18 tables contain records about CPG documents, authors, authorities, used classification and thesaurus codes and auxiliary code-lists. 13 tables contain data used for web interface functions. 18 tables are binding tables.

Several codes of international classification and nomenclature systems can be assigned to the CPG document record in the CCPG database:

1. Medical Subject Headings (MeSH) complex vocabulary thesaurus of the National Library of Medicine One or more MeSH codes can be linked to each CPG document. MeSH code

Tab. 3. Structure of the database table_linked_files.

\begin{tabular}{|l|l|l|}
\hline Column name & Data type & Description \\
\hline file_id & int(11) & serial number of the record \\
\hline file_name & text & link title \\
\hline file_link & text & full definition of the hypertext link (URL) \\
\hline filetype_id & smallint(6) & file type (podle externího čiselníku) \\
\hline file_note & text & link comment \\
\hline file_size & int(11) & file size in kilobytes \\
\hline file_inda & datetime & date and time of the link record insertion \\
\hline file_usid & int(11) & identification of the user, who created the link record \\
\hline file_Icda & datetime & date and time of the link record last change \\
\hline file_Icui & int(11) & identification of the user, who last changed the link record \\
\hline file_status & smallint(6) & $\begin{array}{l}\text { recency type of the linked CPG document - concept of document, valid document or } \\
\text { obsolete document }\end{array}$ \\
\hline file_show & boolean & marks displaying of the link in the user interface \\
\hline file_actualization & date & date of the last actualization of the linked document \\
\hline broken_link & boolean & mark of nonfunctional link made by an automated evaluation tool \\
\hline
\end{tabular}

describes the position of the term naming descriptor in the hierarchical structure. One descriptor can occur on different positions in the hierarchical structure - in this case the most matching hierarchical position is coded.

2. The International Classification of Diseases and Related Health Problems 10th Revision (ICD-10)

One or more three to four letter codes can be linked to each CPG document.

3. Diagnosis-related group (DRG) hospital cases classifying system

One or more five-digit codes can be linked to each CPG document.

4. SNOMED CT (Systematized Nomenclature of Medicine - Clinical Terms) systematically organized collection of medical terminology

One or more unique concepts of this system can be linked to each CPG document. SNOMED CT has not yet been translated into Czech and therefore no Czech CPG document defines related SNOMED CT concepts. We can find appropriate SNOMED CT concepts by translating key terms of the CPG into English or we can map above-mentioned classification into SNOMED CT.
The editor assigns codes of classification systems to the CPG document in the administrative interface of the CCPG. It is possible to assign multiple codes to each document. They can be found as a part of the document in a standalone list in same cases, or it is possible to find them actively disseminated in the whole text. The document does not contain codes of classification systems directly in most cases. Than it is necessary to extract key terms from the document and find appropriate codes manually or through external tools.

The Catalogue of Clinical Practice Guidelines uses also other code lists:

- The list of authorities (primarily professional medical societies), which is continuously extended when adding new CPG documents.

- The list of CPG authors is also continuously extended when adding new CPG documents.

-The list of medical and healthcare specialties.

- Code-lists for geographical competency, language versions or file types.

The main database table _documents consists of 23 columns defining the CPG document (see Table 2). Further information is provided by binding tables connecting above-mentioned code-lists and the table of external links. 
Fig. 2. Screenshot generated by a web browser from the URL http://neo.euromise.cz/kkdp/?akce=mkn_strom shows browsing through hierarchical structure of the ICD classification with hypertext links to ICD codes definitions on the web page of the Institute of Health Information and Statistics of the Czech Republic.

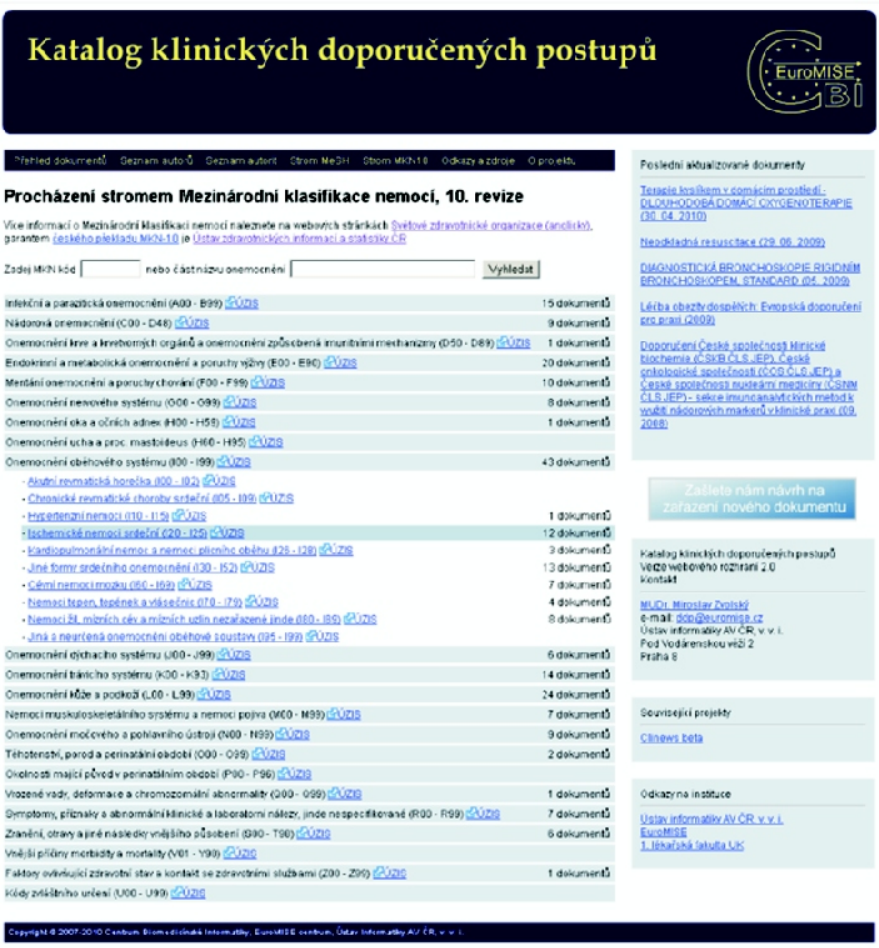

browsing web sites of professional medical societies (using the list placed on the web page of the Czech Medical Association of J. E. Purkyně). We insert the structured description of all CPG documents found on these sites and meeting the above criteria into the CCPG database using the administrative interface. Another way of enlisting a CPG document is using the announcement message generated from the web form, which is a part of the CCPG user web interface. If the visitors of CCPG know the address of an unlisted document, they can announce it to editors using this form.

After creating a new record of the CPG, the editor searches for the maximum amount of information available about the CPG document and adds it to the database using the administrative interface. In the future we count on an active cooperation with CPG document authors, who can complete or confirm the data gathered. Every record has a variable describing the phase of the processing.
This table named_linked_files defines addresses of CPG documents as the Uniform Resource Identifiers. This table consists of other 14 columns defining of each link in detail (see Table 3).

Following criteria were stated for the enlisting the CPG document into the CCPG database:

-The CPG document is accessible in the electronic format via Internet.

- The CPG document is granted by at least one professional authority. It is linked from the web site of the granting authority or the official periodical of this authority. It is placed on the same web site.

- The CPG document is defined in its title or related description as clinical practice guideline, guideline, recommendation, recommended practice, standard, methodical direction or protocol.

- The CPG document is accessible free of charge in the public part of the web presentation with no registration required. It is not password protected and it has no other protection.

Two possible ways of selecting the documents suitable for enlisting in CCPG take place. Since 2007 we have been
Fig. 3. Screenshot generated by a web browser from the URL http://neo.euromise.cz/kkdp/?akce=detail\&dokument=46 - CPG document record details with link to the full text document URL.

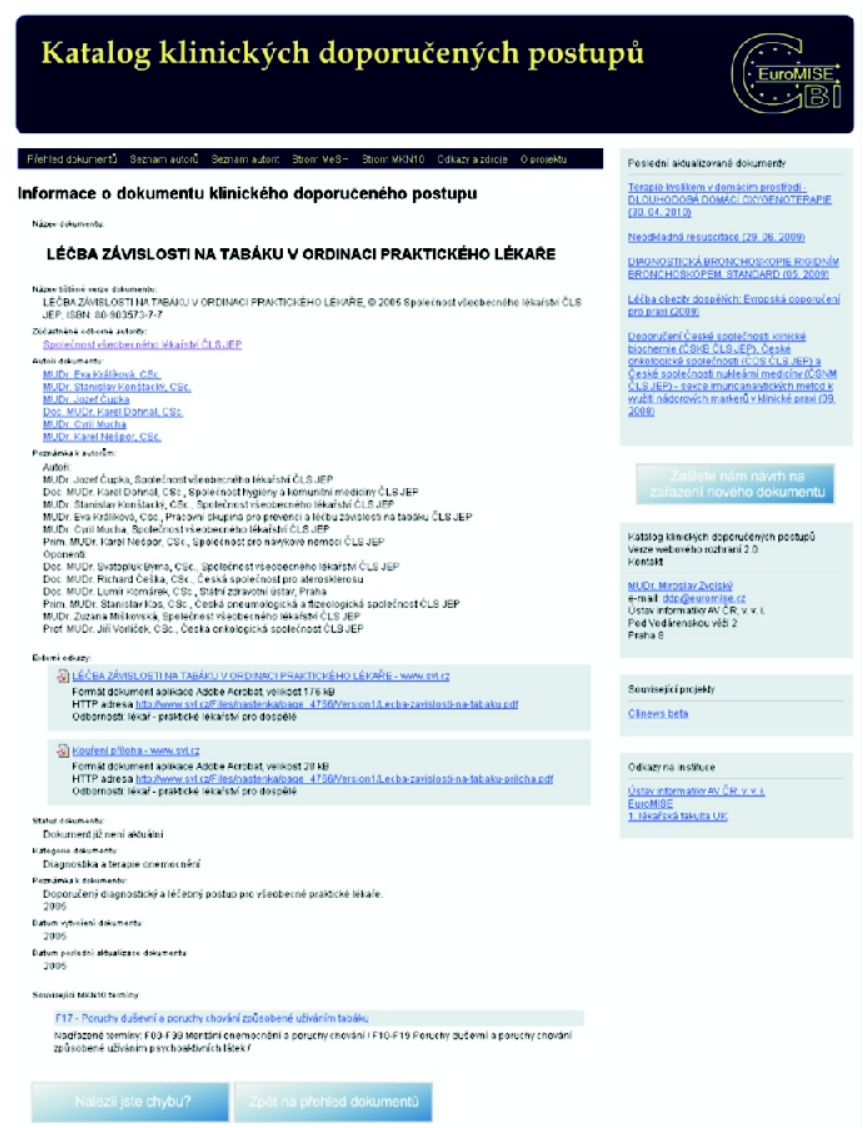


In compliance with this variable the record is listed and displayed on the web interface indicating the completeness and the recency of the record.

We developed a tool for automated browsing and evaluation of recorded links to the CPG documents. This tool analyses returned HTTP status codes for each link. The link is marked as an error and it is highlighted for the editor to correct it, when the error HTTP status code is returned. The editor then analyses an error and they correct or delete the link in the database.

The user interface of the CCPG offers the list of CPG document records ordered by the title or by the date of the last modification. Other possible lists are orders by authors (alphabetically) or by authorities (professional medical societies). Users can browse through the hierarchical tree of MeSH or ICD when searching for the target document by topic (see Figure 2). It is possible to choose and display the detailed information about the particular CPG document, where all available data about the document are printed including hypertext links to the full text document URL (see Figure 3).

\section{Results}

On September 1st, 2010 the database of the Catalogue of Clinical Practice Guidelines contained 562 records of Czech Clinical Practice Guidelines. 12 records were marked as deleted/not existing. 212 records were marked as verified and they were displayed in the user web interface of the CCPG.

The database contained 640 records of linked files of CPG documents. 17 of them were marked as an incorrect link.

On the same date the database contained 491 records of authors of the CPG documents and 91 records of publishing professional medical societies.

Only records of CPGs marked as verified and authors and authorities related to these records are displayed in the freely accessible user web interface of the CCPG. Therefore this interface of the catalogue lists only 212 records of CPG, 430 records of authors and 46 records of authorities.

\section{Discussion}

The database of the CCPG in the current state maps the majority of current publication activities in the field of CPGs accessible via the Internet. The total number of these documents is a minimum of 731 of linked files [7]. 640 of them are recorded in our database (or more precisely 623 existing files).

Our catalogue contains fewer records in comparison with some foreign catalogues of clinical practice guidelines as the Guidelines International Network, the National Guideline Clearinghouse or the National Library of Guidelines [12], [10], [11]. This difference is caused mainly by focusing on documents in the Czech language. The amount of CPG documents in English is much bigger. Not all records in above mentioned catalogues include the reference to the on-line full text version of the CPG document. Comparison with foreign catalogues focused only on the national set of CPG documents or limited on one development organization (e. g. the New Zealand Guidelines Group [16] or the Scottish Intercollegiate Guidelines Network [17]) is more advantageous in the number of records (see Table 3). Our catalogue has more possibilities in ordering records by different categories contrary to foreign catalogues.

Many Czech CPG documents are so incomplete or they do not contain sufficient identification specification that it is necessary to search hard for the missing specification data.
Only 212 records are marked as verified due to limited resources assigned to the maintenance of the catalogue.

Czech CPG documents in most cases do not contain codes of classification and nomenclature systems, but they contain textual information about diagnoses, etiological agents or anatomical structures, which can be found in these classifications. Manual browsing in the classification and searching for the code by the editor is less accurate than these being specified by the author of the CPG. The inaccuracy can arise when the term contained in the textual CPG does not correspond precisely with the term from the classification or it has multiple meanings in the hierarchical structure.

The database of the CCPG offers links to two classifications and a thesaurus commonly used in the Czech health care system (MeSH, ICD, DRG). SNOMED CT has not a Czech translation yet and is of a limited use, but it is the most complex nomenclature system. Filling codes of all four systems in cope with several problems. We have often insufficient information in the source text of the CPG. Terms in these four systems are not always fully matching. When filling codes of these systems properly in all records of CPG the potential for connecting to health information systems (ICD, DRG, SNOMED CT) and bibliographical systems would increase.

Tab. 4. - Comparison of some on-line catalogues of CPG.

\begin{tabular}{|l|l|l|}
\hline Catalogue & Number of records & Records ordered by \\
\hline $\begin{array}{l}\text { Catalogue of Clinical Practice } \\
\text { Guidelines }\end{array}$ & $623(212$ validated $)$ & $\begin{array}{l}\text { author, expert society, } \\
\text { MeSH, ICD }\end{array}$ \\
\hline Guidelines International Network & 7100 & MeSH \\
\hline National Guideline Clearinghouse & 2549 & MeSH, developer \\
\hline National Library of Guidelines & 3220 & specialization \\
\hline New Zealand Guidelines Group & 74 & $\begin{array}{l}\text { therapeutic category, } \\
\text { developer }\end{array}$ \\
\hline $\begin{array}{l}\text { Scottish Intercollegiate Guidelines } \\
\text { Network }\end{array}$ & 120 & topic \\
\hline
\end{tabular}


The database should also contain information about formalised models of CPGs in the form of links to descriptions of these models or to web applications using or displaying these models.

Nowadays, the database does not contain this information because formal models of CPGs do not exist or they are not freely accessible via Internet. In the future the CCPG could serve as an on-line repository for the information about these models.

The database of the CCPG is designed for storing the information about CPG documents published in the Czech language. CPG documents with a wider geographical effect can be valid for the Czech Republic (e.g. documents issued by the World Health Organisation or international professional societies). These documents can also have foreign language versions. The future development of the CCPG will respect and support various language versions of the CPG documents.

The feature of adding information about relevant literature with linking to bibliographical sources like the Medline is another planned modification of the CCPG. The database of the CCPG will be adjusted also in other aspects according to the actual needs.

The aim of the CCPG project is to store information about CPG documents and completely cover all publication activities of professional authorities in the field of CPGs. For this purpose we assume to develop tools for automating processes of checking the link validity and newly also browsing web sites for new CPG documents. We will use tools for better communication with CPG authors. We will try to establish a professional community around the project of the CCPG.

\section{Conclusion}

Since 2007 we have developed the Catalogue of Clinical Practice Guidelines for the purpose of collecting information about Clinical practice guideline documents available for the Czech Republic. The component of this project is a database of CPG records in the MySQL format, which can have further usage in decision support systems. On September 1st, 2010 the database included 550 records of active CPG documents in the total of 623 valid files. The database will be extended and adjusted to the publication activity of professional authorities in the Czech Republic.

\section{Acknowledgment}

CCPG development is supported by the project 1 M06014 of the Ministry of Education, Youth and Sports CR.

This work was supported by the grant SVV2010-265513.

\section{References}

[1] Líčeník R.: Klinické doporučené postupy. Výukový portál LF UP Olomouc [online] 20.11.2009, poslední aktualizace 20.11.2009 [cit. 2010-09-24], dostupný z: http://mefanet. upol.cz/clanky.php?aid=38

[2] Field M.J., Lohr K.N.: Guidelines for Clinical Practice: From Development to Use, NATIONAL ACADEMY PRESS, 1992

[3] Suchý M.: Příručka pro autory a oponenty vývoje klinických doporučených postupů, Národní referenční centrum [online] 1. 9. 2010, dostupný z: http://www.sopr.cz/ standardy/dokumenty/dokument_open.php?doc $=3$

[4] Česká kardiologická společnost, http://www.kardio.cz

[5] Česká lékařská společnost Jana Evangelisty Purkyně, http://www.cls.cz

[6] Těšínová J.: Právní aspekty poskytování zdravotní péče v ČR, Medical Tribune 18/2010, dostupný z: http://www.tribune.cz/ clanek/18816-pravni-aspekty-poskytovanizdravotni-pece-v-cr
[7] Zvolský M.: Základní parametry dokumentů doporučených postupů českých lékařských společností publikovaných prostřednictvím Internetu, Doktorandské dny'09, MATFYZPRESS; 2009, dostupný z: http://www.cs.cas.cz/hakl/doktorandskyden/files/2009/sbornik-dd-2009.pdf

[8] Vnitřní lékařství, http://www.vnitrnilekarstvi.cz

[9] Národní referenční centrum, http://www.nrc.cz

[10] National Guideline Clearinghouse, http://www.guidelines.gov

[11] National Library of Guidelines, http:// www.library.nhs.uk/guidelinesfinder

[12] Guidelines International Network, http://www.g-i-n.net

[13] Zvolsky M.: Katalog lékařských doporučených postupů v ČR, Doktorandské dny'08, MATFYZPRESS; 2008, dostupný z: http://www.cs.cas.cz/hakl/doktorandskyden/files/2008/sbornik-dd-2008.pdf

[14] Buchtela D., Peleska J., Zvolsky M,. Zvarova J.: Medical knowledge representation system, Stud Health Technol Inform. 2008;136:377-82.

[15] Shiffman R.N., Shekelle P., Overhage J.M., Slutsky J., Grimshaw J., Deshpande A.M. Standardized reporting of clinical practice guidelines: a proposal from the Conference on Guideline Standardization. Ann Intern Med. 2003 Sep 16;139(6):493-8

[16] New Zealand Guidelines Group, http://www.nzgg.org.nz

[17] Scottish Intercollegiate Guidelines Network, http://www.sign.ac.uk

\section{Contact}

MUDr. Miroslav Zvolský

Centre of Biomedical InformaticsInstitute of Computer Science AS CR

Pod Vodárenskou věží 2

18207 Prague 8

Czech Republic

e-mail: zvolsky@euromise.cz 